\title{
The Problem of Late-Preterm (Near-Term) Births: A Workshop Summary
}

\author{
TONSE N. K. RAJU \\ Center for Developmental Biology and Perinatal Medicine, National Institute of Child Health and Human Development, National Institutes \\ of Health, Bethesda, Maryland 20952
}

$\mathrm{I}^{\mathrm{n}}$ n July 2005, the National Institute of Child Health and Human Development (NICHD) of the National Institutes of Health invited a team of experts to address many aspects related to the care and outcome of near-term infants. The Pediatric Academic Societies (PAS) also organized a symposium at its annual convention on this topic in San Francisco. The NICHD Workshop panel discussed the epidemiology, etiology, biology of maturation, clinical care, surveillance, and public health issues related to this topic, which are summarized elsewhere (1). Individual presentations from the Workshop are in two issues of Seminars in Perinatology (Volume 30, 2006). In this report, I provide a brief summary from the NICHD Workshop and the PAS symposium.

\section{BACKGROUND}

One of the many objectives of the U.S. Healthy People 2010 is to reduce preterm birth rate to $7.6 \%$ by 2010 . However, there has been a gradual increase of up to $0.2 \%$ per year in the preterm birth rate over the past decade, resulting in an all time high rate of $12.5 \%$ in 2004 . This represents a $37 \%$ increase compared with the 1981 rate of $9.1 \%$. Nearly two thirds of the increase has been attributed to an increase in the proportion of near-term births (referred to as late-preterm, see below). Because this group is at high risk of perinatal morbidity and mortality $(2,3)$, there has been a growing interest in this topic.

\section{TERMINOLOGY: LATE PRETERM, NOT NEAR TERM}

Preterm birth is defined as births occurring before the completion of 37 wk of gestation (259 d) (4). However, there is no uniformity in the use of the phrase near-term. The Workshop panel proposed that infants born between wk 34 and 36 (d 239 through 259) of gestation ought to be called late preterm instead near term $(1,5)$. Because the latter may imply that these infants are almost term and mature, there is the possibility of underestimating their risks, less diligent evaluation, and poor follow-up. The panel noted that there is no such thing as

Received July 24, 2006; accepted July 28, 2006.

Correspondence: Tonse N. K. Raju, M.D., 6100 Executive Blvd., Room 4B03, Bethesda, MD 20952; e-mail: rajut@mail.nih.gov

DOI: 10.1203/01.pdr.0000246074.73342.1e "normal preterm infant," and the phrase "late preterm" conveyed better the sense of vulnerability than did the phrase "near term."

\section{EPIDEMIOLOGY: ONE PRETERM INFANT PER MINUTE}

With 4 million births annually in the United States, a $12.5 \%$ preterm birth rate computes into a staggering figure of one preterm infant born each minute. It is also noteworthy that in all preterm gestations, there has been an increase in cesarean births and induced deliveries (6). This is concerning because there is a large proportion of induced births in late-preterm gestations with documented etiology (6). We also do not know the proportion of preterm births attributable to specific medical conditions at the national level. Some explanations for the increasing preterm birth are increasing proportion of pregnant women older than $35 \mathrm{y}$ of age, medically indicated deliveries secondary to better surveillance of the mother and the fetus, attempts to reduce stillbirths, and stress from a variety of sources. However, the panel concluded that nationwide epidemiologic studies are needed to inform the etiology of increasing preterm births, especially in the late-preterm gestations.

\section{OBSTETRICIANS' DILEMMA}

The obstetrician faces many challenges while managing women in labor in any preterm gestation. These include balancing the benefits of immediate delivery against the risks of prematurity and assessing the benefits of expectant management versus the potential risk of compromising maternal and fetal health. Furthermore, there are well-known, medically indicated causes of preterm births, such as placental abruption, placenta previa, bleeding, infection, hypertension, multiple pregnancy (7), preeclampsia, idiopathic preterm labor, premature rupture of membranes, and intrauterine growth restriction. However, with the exception of multiple pregnancies, there is no indication that the prevalences of other conditions are on the increase. Thus, some experts contend a sizable number of late-preterm births can be prevented (8); however, more studies are needed to substantiate this claim. 


\section{MEDICAL PROBLEMS}

Compared with term infants, those born at late-preterm gestations suffer from higher rates of morbidity and mortality $(2,3,9-14)$. Some of these include respiratory distress, hypoglycemia and hypothermia, prolonged physiologic jaundice, apnea, feeding difficulties, late neonatal sepsis, and sudden infant death (13). Despite the recommendations by the American Academy of Pediatrics (15), often late-preterm infants are discharged early, which can prove to be risky $(16,17)$.

\section{LONG-TERM OUTCOME}

At 35 wk of gestation, the surface of the brain has significantly fewer sulci, and the brain weighs only $60-65 \%$ of the full-term infant's brain (12). Although the implication of the brain immaturity at late-preterm gestations needs to be studied, some long-term outcome studies have raised concern. Of the 869 low birth weight infants, $19 \%$ to $20 \%$ born at $34-37$ wk had clinically significant behavior problems at 8 y of age (18), a rate higher than those in the term cohorts from the same population (19).

\section{IMPACT ON PUBLIC HEALTH AND HEALTH CARE POLICY}

Late-preterm infants are not typically considered at high risk. In some states, birth weight $\leq 1500 \mathrm{~g}$ is used to define high risk. However, high-risk status ought to be determined based on other criteria, not just an arbitrary birth weight. There is also a considerable variation in medical care for newborn infants, especially in the use of mechanical ventilation and nutritional support, despite similar birth weights and admission illness severity (20). Although the reasons for such trends are unknown, variation may lead to increased hospital costs or suboptimal care.

\section{FUTURE DIRECTIONS FOR RESEARCH}

The Workshop panel made detailed proposal for additional research on the topic of late-preterm births (1). Some these are refining the assessment of pregnancy duration and fetal maturity, epidemiology of late-preterm births at different levels of care, studies on the indications for preterm births and to assess if any can be prevented, studies on the cause-specific and gestational-age specific morbidity and mortality, and evaluation of postdischarge outcomes and long-term morbidity.

\section{SUMMARY AND CONCLUSIONS}

Since nearly two thirds of the increase in preterm births can be attributed to the increasing rates of late-preterm births, research is urgently needed on this topic. We also need to educate the health care personnel at all levels that even seemingly healthy, latepreterm infants are physiologically immature, and therefore they should be diligently evaluated, monitored, and followed.

\section{REFERENCES}

1. Raju TN, Higgins RD, Stark AR, Leveno KJ 2006 Optimizing care and outcome for late-preterm (near-term) infants: a summary of the workshop sponsored by the NICHD. Pediatrics 118:1207-1214

2. Kramer MS, Demissie K, Yang H, Platt RW, Sauve R, Liston R 2000 The contribution of mild and moderate preterm birth to infant mortality. Fetal and Infant Health Study Group of the Canadian Perinatal Surveillance System. JAMA 284:843-849

3. Shapiro-Mendoza CK, Tomashek KM, Kotelchuck M, Barfield W, Weiss J, Evans S 2006 Risk factors for neonatal morbidity and mortality among "healthy," late preterm newborns. Semin Perinatol 30:54-60

4. American Academy of Pediatrics and the American College of Obstetricians and Gynecologists. 2005 Guidelines for Perinatal Care, 5th Ed. American Academy of Pediatrics, Elk Grove Village, IL, pp 211-220

5. Engle WA 2006 A recommendation for the definition of "late preterm" (near-term) and the birth weight-gestational age classification system. Semin Perinatol 30:2-7

6. Davidoff MJ, Dias T, Damus K, Russell R, Bettegowda VR, Dolan S, Schwarz RH, Green NS, Petrini J 2006 Changes in the gestational age distribution among U.S. singleton births: impact on rates of late preterm birth, 1992 to 2002. Semin Perinatol 30:8-15

7. Lee YM, Cleary-Goldman J, D'Alton ME 2006 Multiple gestations and late preterm (near-term) deliveries. Semin Perinatol 30:103-112

8. Gilbert WM, Nesbitt TN, Danielsen B 2003 The cost of prematurity: quantification by gestational age and birth weight. Obstet Gynecol 102:488-492

9. Wang ML, Dorer DJ, Fleming MP, Catlin E 2004 Clinical outcomes of near-term infants. Pediatrics 114:372-376

10. Escobar GJ, Claark RH, Green JD 2006 Short-term outcomes of infants born at 35 and 36 weeks gestation: we need to ask more questions. Semin Perinatol 30:28-33

11. Jain L, Eaton DC 2006 Physiology of fetal lung fluid clearance and the effect of labor. Semin Perinatol 30:34-43

12. Escobar GJ, Clark RH, Greene JD 2006 Short-term outcomes of infants born at 35 and 36 weeks gestation: we need to ask more questions. Semin Perinatol 30:28-33

13. Hunt CE 2006 Ontogeny of autonomic regulation in late preterm infants born at 34-37 weeks postmenstrual age. Semin Perinatol 30:73-76

14. Kinney HC 2006 The near-term (late preterm) human brain and risk for periventricular leukomalacia: a review. Semin Perinatol 30:81-88

15. Tomashek KM, Shapiro-Mendoza CK, Weiss J, Kotelchuck M, Barfield W, Evans S, Naninni A, Declercq E 2006 Early discharge among late preterm and term newborns and risk of neonatal morbidity. Semin Perinatol 30:61-68

16. Escobar GJ, Gonzales VM, Armstrong MA, Flock BF, Xiong B, Newman TB 2002 Rehospitalization for neonatal dehydration: a nested case-control study. Arch Pediatr Adolesc Med 156:155-161

17. American Academy of Pediatrics, Committee on Fetus and Newborn 2004 Hospital stay for healthy term newborns. Pediatrics 113:1434-1436

18. Gray RF, Indurkhya A, McCormick MC 2004 Prevalence, stability, and predictors of clinically significant behavior problems in low birth weight children at 3,5 , and 8 years of age. Pediatrics 114:736-743

19. McCormick MC, Workman-Daniels K, Brooks-Gunn J 1996 The behavioral and emotional well-being of school-age children with different birth weights. Pediatrics 97:18-25

20. McCormick MC, Escobar GJ, Zheng Z, Richardson DK 2006 Place of birth and variations in management of late preterm ("near-term") infants. Semin Perinatol 30:44-47 